\title{
Using Performances in a Flipped Classroom Setting
}

\author{
James A. Bernauer
}

\begin{abstract}
The purpose of this study is to explain how performances are used within a flipped classroom environment in a university educational psychology class. This instructional approach also incorporates the concept of "integrated assessment" where assessment and instruction are intimately connected. Examples of student-led instruction using performances are provided. Results of a teacher-developed assessment administered during the past several years to elicit student evaluations of these instructional practices have provided evidence that using this instructional approach is effective for most but not all students.
\end{abstract}

\section{Teacher-Centered to Student-Centered Instruction}

As I stood at the podium of a master's level class in Educational Psychology in 2013 lecturing students about how important it is to allow students to take an active role in their own learning, I stopped in midsentence because I realized that I was not practicing what I was preaching-and frankly, I was also sick of hearing myself talk! While I spoke about the need for more student-centered instruction, I modeled its opposite-teacher-centered instruction. It is to that particular moment that I can trace back my development of instructional strategies that are decidedly more student-centered.

As time moved on from this seminal moment, I began to develop instructional strategies that required a lot more up-front preparatory work but less "teaching" during the actual class session; rather, I found myself "facilitating." I found that sharing control of a classroom required that students be given guidance in advance of a class session so that they would be prepared to assume a greater ownership of their own learning. There was a need to develop strategies that balanced teaching and learning responsibilities between teacher and students that blurred the distinction between both teachers and students and teaching and learning. If we think of teaching as transferring an organized body of knowledge from teacher to learner, then indeed a sharp distinction can be made between teaching and learning. However, if we view learning as an active process of co-constructing knowledge and understanding and creating new and novel ideas and concepts, then all of us are student-teachers as well as teacher-students. In fact, we might even say that if there are 25 students in a classroom then there are potentially 26 teachers. During these past six years, I have certainly found that to be the case. 


\section{Constructivist Learning Theory and Flipping}

Different learning theories have been developed to help us understand how we learn and, by implication, how we might teach (Bernauer \& Tomei, 2015). The application of these theories is context-dependent on the content to be learned as well as the developmental readiness of learners. For example, Behavioral Learning Theory works great for tasks that are well defined such as learning to type or the alphabet. However, as the complexity of learning increases, we may find that cognitive theories are more effective. The learning theory that I have found to be most useful when teaching at the university level is Constructivist Learning Theory (CLT) that has its roots in the work of Lev Vygotsky (1978), Jean Piaget (1954), and John Dewey (1913), among others. In essence, CLT recognizes that each of us needs to "re-invent the wheel" in order to come to "own" knowledge and to create new knowledge. This constructivist approach is decidedly nonlinear at times, meaning that rather than viewing learning solely as a step-by-step cumulative process, it is also characterized by insights and intuitive leaps (see Polanyi, 1958). I also stress to students that facts in isolation are meaningless without contextual understanding. I demonstrate this by pointing to a glass that is filled to the halfway mark and ask the proverbial question whether the glass is half empty or half full. I stress that our assessment is influenced by considerations such as how thirsty we are, the scarcity of water, and so on. The physical fact of the liquid reaching the halfway mark is undeniable; however, these other considerations give cogency to responses. For example, 58,000 American military deaths in the Vietnam War can be considered large or small depending on our values as well as what we use for comparison, such as the Korean War (34,000 deaths) or WWII (417,000 deaths).

Based on the important role that Constructivist Learning Theory plays in learning, I tried different ways to meld this theory with creating a more performance-based classroom. I use a learning platform (Blackboard) to provide students with guidance for assuming more control during class time and to facilitate achieving desired course outcomes. Table 1 illustrates how two teams were guided to engage the class in learning about Behavioral Learning Theory. Each team comprises four to six students who know in advance what they are expected to do at upcoming classes such as in Table 1. This instructional process can be considered a type of "flipping" where homework becomes the focal point of classroom instruction, rather than a sidebar of instruction. The particular version of flipping I use is characterized by collaborative learning, student performances, and integrated assessment that has been designed to promote students' active engagement in their own learning.

\section{Performances and Integrated Assessment}

Performances span professions and subject areas and performance assessment can be used to evaluate products, procedures, as well as performances themselves (see, for example, Kubiszyn \& Borich, 1993; Morris, Fitz-Gibbon, \& Lindheim, 1987), although dramatization and simulation still seem underused in typical classrooms. Performances are often used to assess both preservice and inservice teachers (Castle \& Shaklee, 2006), while how to analyze these performances in order to obtain useful and actionable evidence is sometimes a challenge (see Bastian, Lys, \& Pan, 2018). Maxwell (2012) argues

54 | LEARNing Landscapes | Spring 2020, Vol. 13 
that action research is related to authentic assessment in higher education for the professions including teacher preparation programs and concludes:

In addition to the argument that action research is an appropriate part of the curriculum in professional education, the action research report was judged as an authentic task. It is especially appropriate as a capstone assessment, that is, as a culminating performance. (p. 695)

I have found this same kind of linkage among research, assessment, and performances in my own teaching and related scholarly inquiry.

Table 1 represents a recent student learning assignment for a class in Educational Psychology. I develop these team-based performance plans for classes in advance of the start of a new semester using Blackboard as the learning platform that students access prior to each class.

Table 1: How Children Learn

Topic: How Children Learn (Behavioral Learning Theory)

Team Preparation: 10 AM-10:10 AM

Team-Led Discussions:

Team 3: 10:10 AM-10:30 AM

Team 4: 10:30 AM-10:50 AM

Team 3 Tasks: (Try to integrate the Smartboard, YouTube videos, Maker Space, or other tools with your discussion!)

1. Narrator/Timekeeper: Tell us what we are supposed to learn based on pages 254-258 of our text, why it is important, and how it links to our assignments (Desk Drawer Reminder 2 (DDR-2); Critical Assignment (CA), Field Experiences (FE), team-developed Student-Centered Teaching and Learning Model (SCTLM), and our future classrooms!

2. Team: Can you dramatize the scenario found on pages 255-256 and point out to us what lessons we might learn from it?

3. Team: Could you explain to us "classical conditioning" and then ask the class to do the "Stop \& Think" (p. 256)?

4. Team: Use the document camera to project the Guidelines found on page 258 and point out and briefly explain the three bolded headings. Then, how about dramatizing one example under each bold heading?

5. Team: How about asking one member of Team 1 and one member of Team 2 what they found to be of most interest?

6. Narrator: Remind us how what we learned connects to our future "learning classrooms" and DDR-2!

Team 4 Tasks: (Try to integrate the Smartboard, YouTube videos, Maker Space, or other tools with your discussion!)

7. Narrator/Timekeeper: Tell us what we are supposed to learn based on pages 258-264 of our text, why it is important, and how it links to our assignments (Desk Drawer Reminder 2 (DDR-2); Critical Assignment (CA), and your team-developed Student-Centered Teaching and Learning Model (SCTLM), and our future classrooms!

8. Team: (Stop \& Think, p. 259): Project Stop \& Think and involve the class in a dramatization about operant conditioning!

9. Team (pp. 259-260): Draw the Reinforcement sequence from page 259 and the Punishment sequence on page 260 on the Smartboard. Now explain the difference!!

10. Team (Fig. 20.1, p. 261): Project this figure and ask students to relate their own experiences about reinforcement.

11. Team: Based on pages 262-263, could you provide a brief description of the importance of "antecedents" in behavioral learning and then give a short example of Effective Instruction Delivery, Cueing, and Prompting? Try and get class members to join in!

12. Team: Choose one member of Team 1 and one member of Team 2 and ask them what they found to be of most interest!!

13. Narrator: Remind us how what we learned connects to our future "learning classrooms" and DDR-2! 
Notice that the topic and allotted times are given first to help students link content to the realities of classroom learning, especially to that most precious of commodities-time. Students are also reminded to stretch their imaginations in terms of what modalities and instructional tools can be used to engage students in the discussion that they will lead including the Smartboard, YouTube, and objects that can be constructed in our Maker Space area. Students have also used glasses of water, corks, and pendulums in order to engage their classmates in learning in unique ways. The student-elected Narrator/Timekeeper plays a prominent role by pointing out the connections to assignments/assessments both prior to and following the student performance, which is consistent with the concept of integrated assessment. These assignments are designed to both guide student-led performances as well as to serve as additional reinforcement for what is being learned. The Narrator/Timekeeper is tasked not only with directing the entire "performance," but also with providing an "advance organizer" (Mayer, 1984) at the beginning of the session and also a brief recap at the end of the discussion. An essential part of both these components is connecting student learning to assignments. All assignments are given to students on the first day of class - there are no other assessments or tests. I make clear to students that, unlike midterms and finals, these assignments should be worked on as they are learning in class and while their team is preparing their discussions. I define this tight connection between assignments and instruction via team-led performances as "integrated assessment" (Bernauer \& Cress, 1997) where students see that assessment can most profitably be seen as an integral component of instruction. Tasks were developed based on specific assignments (in this case DDR-2) with an emphasis on student-centered learning and performances. Table 2 displays DDR-2, which laid the basis for the performance tasks demonstrated by students in Table 1.

Table 2: Desk Drawer Reminder

\section{Desk Drawer Reminder (DDR-2): Learning Theories, Multiple Intelligence, and Metacognition}

\section{My Future Classroom}

Begin by briefly describing the classroom setting where you hope to teach someday in terms of location, grade level, and subject matter, and why you want to teach in this setting. Next, write something to yourself like "Sara, how is it going? How about remembering back to the theorists and their concepts that you discussed with classmates?" Then begin to develop your thoughts regarding the six questions below — this is what integrated assessment is all about-connecting learning and assessment!

\section{Questions I Should Ask Myself}

Your task is to respond thoughtfully to the questions below in relation to your future classroom setting. You know that students who feel cared for and are engaged in learning not only achieve at higher cognitive, emotional, moral, physical, and social levels, but also present far fewer "classroom management" problems- that is why you are writing this reminder to yourself!

1. What concepts related to intelligence as described by Cattell, Horn, Carroll, Sternberg, and Garner will I use to engage students in learning, minimize disruptions, and construct a learning classroom? (Module 11)

2. What concepts related to metacognition, learning strategies, problem solving, creativity, and critical thinking will I use to engage students in learning, minimize disruptions, and construct a learning classroom? (Modules 24-26)

3. What concepts related to Behavioral Learning Theory will I use to engage students in learning, minimize disruptions, and construct a learning classroom? (Modules 20-21)

4. What concepts related to Cognitive Learning Theory will I use to engage students in learning, minimize disruptions, and construct a learning classroom? (Modules 22-23)

5. What concepts related to Social-Cognitive Learning Theory will I use to engage students in learning, minimize disruptions, and construct a learning classroom? (Module 30)

6. What concepts related to Constructivist Learning Theory will I use to engage students in learning, minimize disruptions, and construct a learning classroom? (Modules 27-28) 
I refer to this intimate connection between these learning performances and assessment as integrated assessment (Bernauer \& Cress, 1997). I also strive to construct assignments with a perceived value and usefulness beyond a particular course, whether it is undergraduate or doctoral level, by designing them within the context of anticipated future professional roles. As you can see, the name of this assignment DDR-2 stands for "Desk Drawer Reminder" to try and help students see that what they learn today should be useful in their future careers in teaching, training, coaching, or any other profession.

\section{Performances in Action}

The class that has been referenced above in both Table 1 and Table 2 is an undergraduate educational psychology class comprising primarily Freshmen and Sophomore students who are in the teacher education program to prepare students to teach from preschool through high school, although there are typically a few students in counseling and other nonteaching areas. However, it is important to note that I use the same type of instructional strategy across subjects and levels, including a master's level course in learning theories as well as doctoral courses in qualitative research and statistics. It is also important to note that some of these courses are online while others are in the traditional classroom. While "performances" are not as pervasive in online course offerings, I still try to think of ways to include them and also maintain the integrated assessment structure.

Since performances can probably best be described using pictures as well as words, I have included several photographs that capture various kinds of student-led performances after first having obtained written consent from these students to include these pictures in any subsequent publications as well as Institutional Review Board (IRB) approval. It is important to remember that these "performances" are rooted in the goals and objectives of the course as described in the course syllabus and as operationalized by the team tasks as provided to students for the entire semester at the beginning of the course on Blackboard as exemplified in Table 1. These performances have also been designed not only to connect directly to assignments, but also to promote and facilitate both reflection and metacognition among members of student teams (see Kaplan, Silver, Lavaque-Manty, \& Meizlish, 2013). The following photos were taken during a 15-week period, which was the duration of the educational psychology class. As described earlier, students know in advance what and when they will need to "perform"; in fact, they can review the entire 15-week schedule at the beginning of the course. I have found that it is extremely important to follow the advice of Cooper and Garner (2012) when trying to create a performance-based "learning classroom" by focusing first on developing relationships with and among students so that they feel a comfort level required to work closely together and to come and trust each other when they get in front of other class members. In addition to teams communicating and working together outside of class, they also have 10 minutes at the beginning of class (see Table 1) to finalize their discussions and dramatizations. Figure 1 shows two team members demonstrating how they might engage students in critical thinking using oranges to demonstrate instances of buoyancy. 
James A. Bernauer

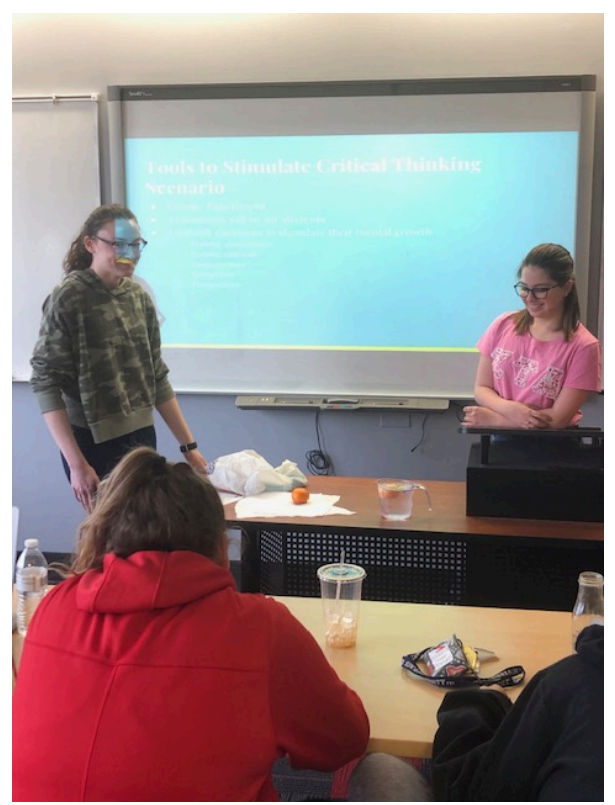

Fig. 1: Using oranges to demonstrate buoyancy

It should be noted that unlike "presentations," the objective here is for teams to engage other students in performance such as this by asking questions of the class and encouraging them to participate in the performance. Figure 2 shows the "advance organizer" that a team used as a prelude to discuss the benefits and drawbacks of requiring memorization.

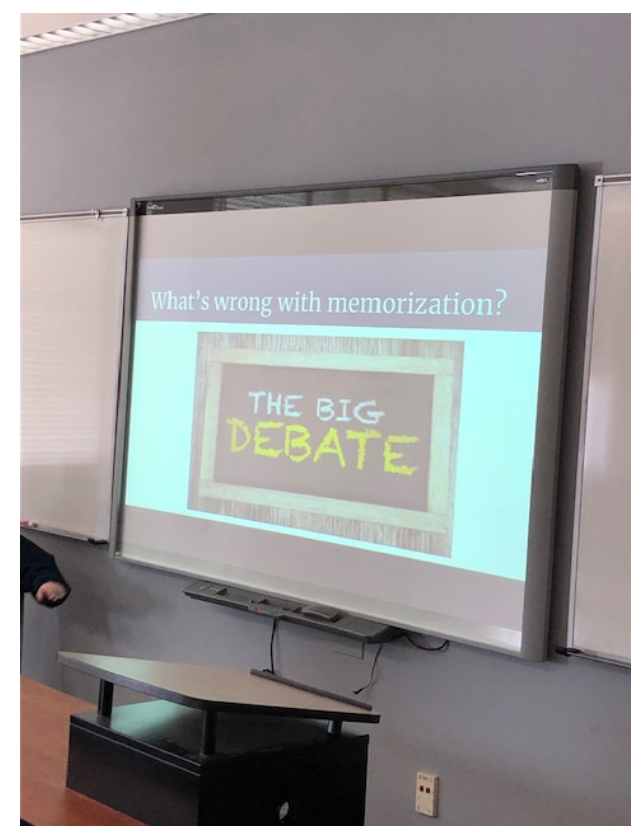

Fig. 2: Advance organizer

Because this debate had multiple participants, there were several instances of different students promoting their points of view. Figure 3 shows a particular instance where there was a great deal of humor and great acting in relation to whether we should promote memorization as a major component of schooling. 


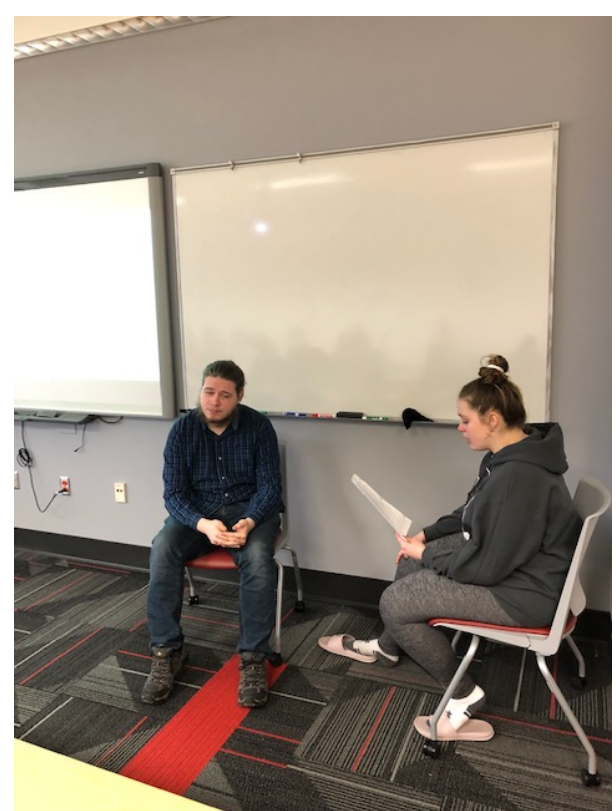

Fig. 3: Memorization as a component of schooling

Because student-teams are the heart of all learning activities, students spend a great deal of time between classes and also before each class discussing and planning how they will respond to their "script" (see Table 1). Figure 4 captures the members of Team 3 collaborating on their upcoming performance.

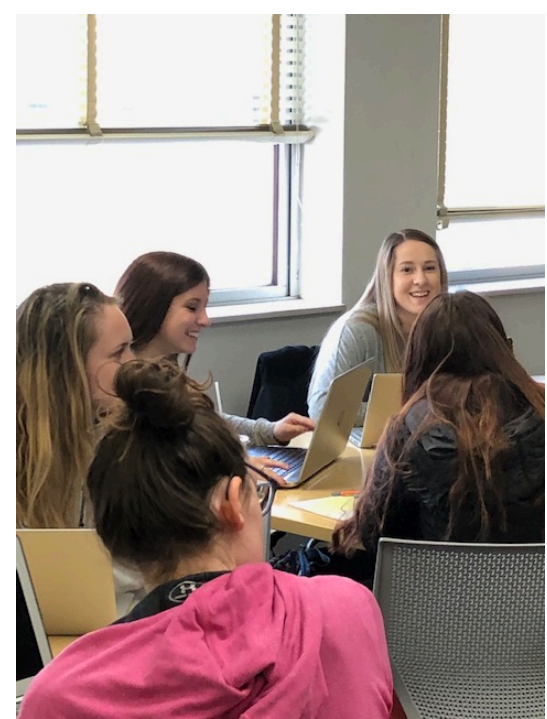

Fig. 4: Collaboration

One of the things that is sometimes overlooked in classrooms is the physical layout, especially in high school and college. Several of our classrooms have been changed so that the furniture is modular and easy to group and regroup depending on the type of performances. This is certainly true in teacher preparation programs where simulation is needed in order to show instances of effective teaching and classroom management. Figure 5 shows members of Team 4 demonstrating how they would start off the school year with clear rules and how positive and negative reinforcement can be used to promote student engagement. 
James A. Bernauer

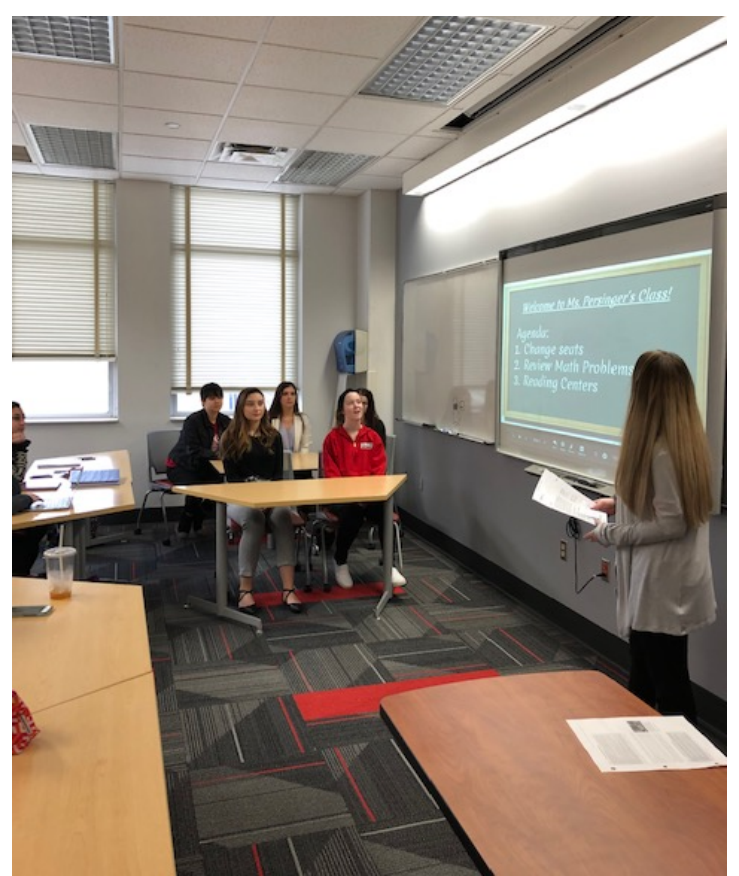

Fig. 5: Positive and negative reinforcement to promote student engagement

The advantages of modular furniture can also be seen in Figure 6 where three members of Team 3 are dramatizing the "Stop and Think" segment that was designed to ask a prospective teacher how she might use classical conditioning in the classroom. The narrator and the "referee" then engaged the rest of the class to build on her responses.

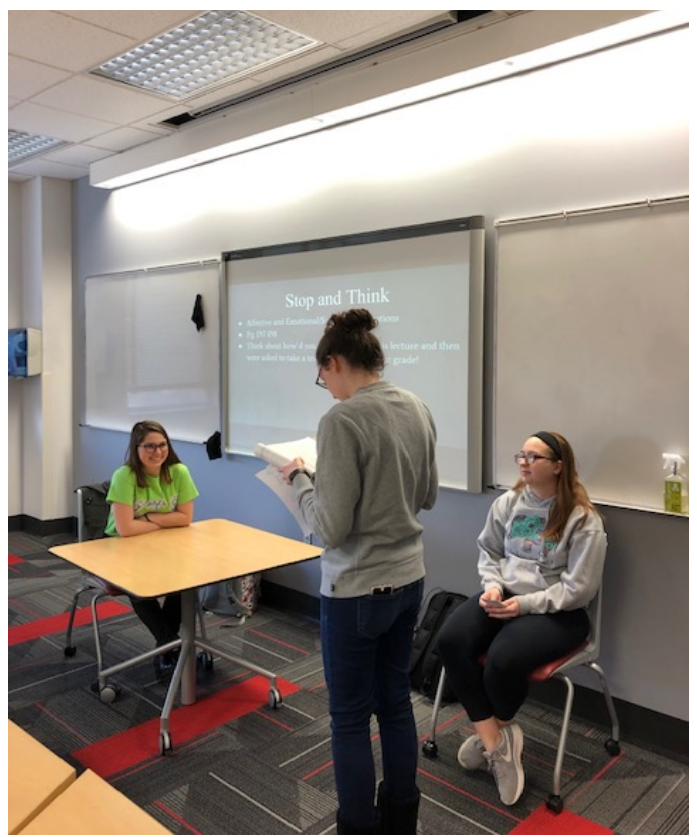

Fig. 6: Classical conditioning in the classroom 
As noted earlier, teams prepare for their performances both in between classes and at the beginning of class. Figure 7 illustrates how Team 3 members used the time prior to class to finalize their performances, especially the roles that each member will play. Here again, the long tables were rearranged to facilitate planning among team members.

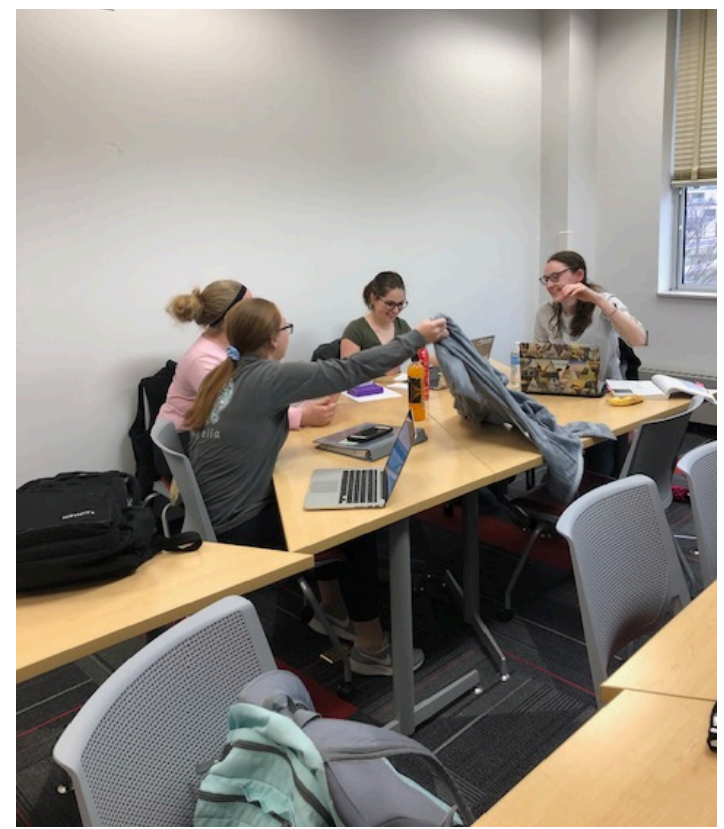

Fig. 7: Planning among team members

All of the performances illustrated here and those that were done during the entire semester were built around the idea of integrated assessment and a "learning classroom" versus a "managed classroom" as described by Cooper and Garner (2012) that is incorporated into all assignments such as Desk Drawer Reminder-2 (see Table 2). Teams routinely incorporate messages that capture the differences between the two types of classrooms (Figure 8).

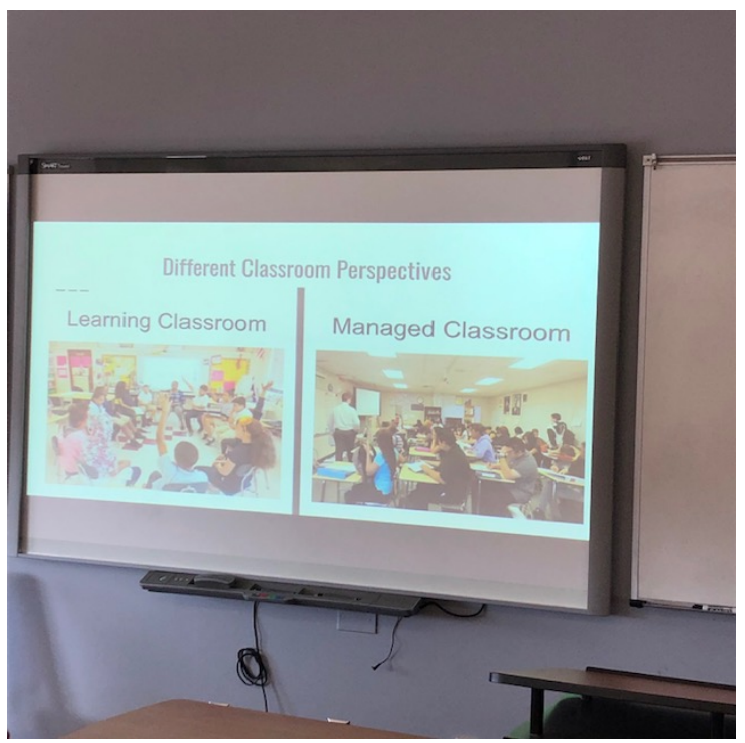

Fig. 8: Differences between two types of classrooms 
The critical connections between performances and assignments are also discussed or displayed at the end of each performance as seen in Figure 9.

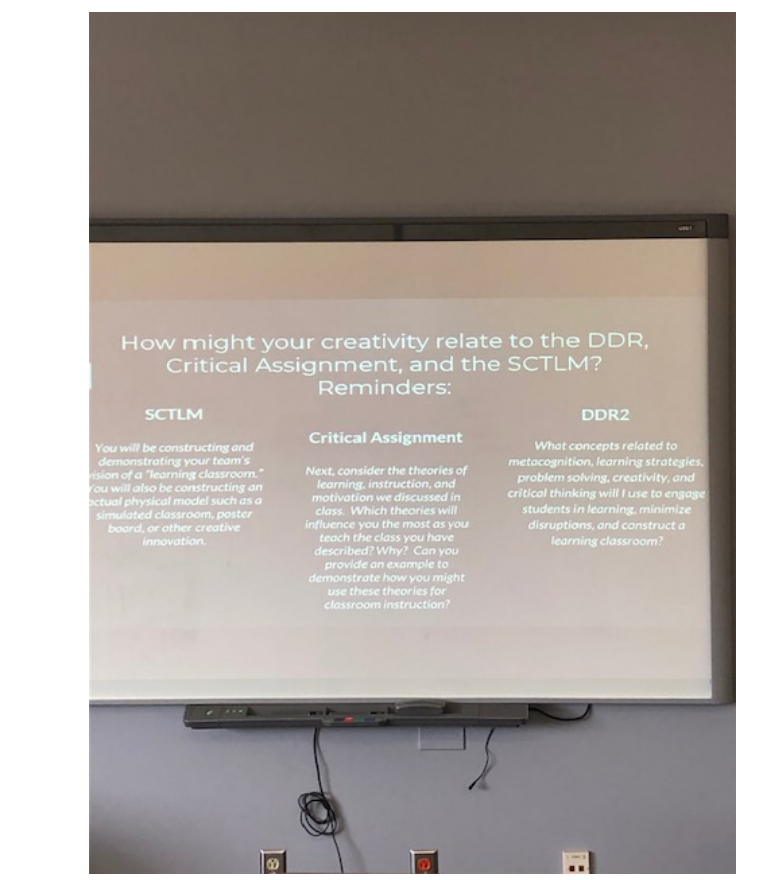

Fig. 9: Critical connections between performances and assignments

\section{Product Performance}

While the Desk Drawer Reminders (DDRs) and Critical Assignment (middle and last columns of Figure 9) are completed individually by each student, because they are intimately connected to team performances, they are also indirectly collaborative. I stress to students that this kind of problem-solving mirrors real life more authentically where the Vygotskian ideas of cooperative learning, scaffolding, and using "cultural tools" are quite evident (see Vygotsky, 1978). To an even greater degree, the "StudentCentered Teaching and Learning Model" (SCTLM) (first column in Figure 9) is a team assignment that was designed to give each team the opportunity and challenge to collaborate during the course of the term and construct a model that illustrates their perspective on the most important concepts that we discussed and to integrate these concepts into a visual model. Even though the SCTLM is not due until the end of the semester, I encourage students to begin planning and working on them early on as new ideas and concepts are discussed. Teams use their SCTLM as the focal point for their final performance while they explain what the model is intended to convey in terms of developing a learning classroom. Figure 10 shows Team 1 in action as they engage the rest of the class by explaining the rationale and concepts integral to their model for a 2nd-grade classroom while Figure 11 shows Team 2 as they describe their version of the SCTLM for a 4 th-grade classroom. 


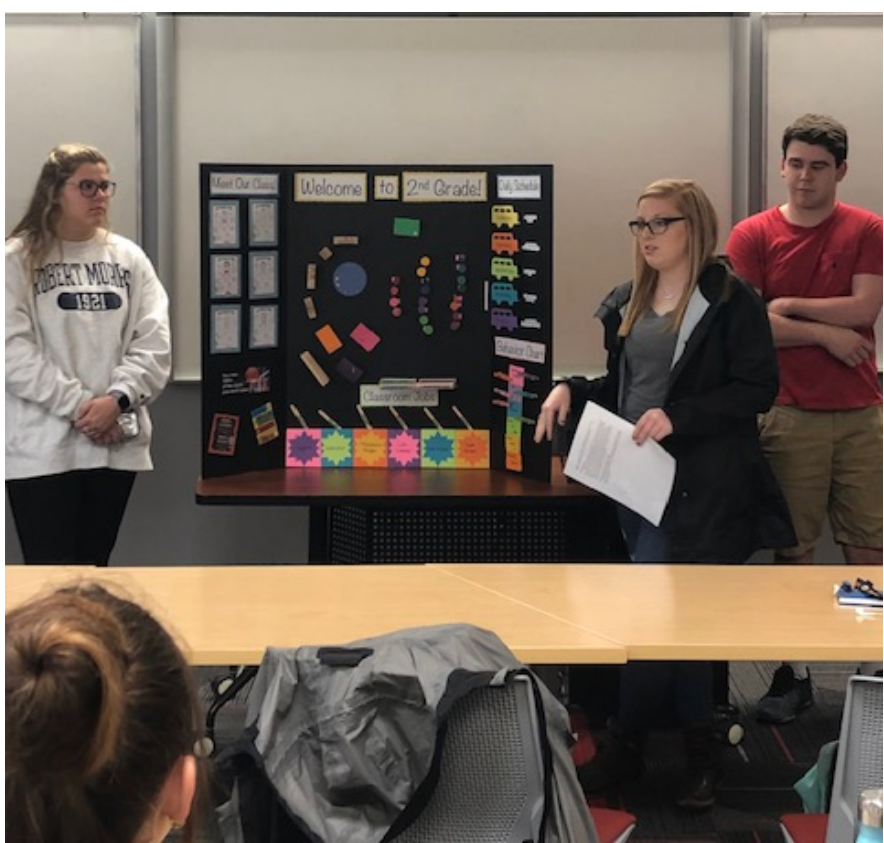

Fig. 10: Student-centered teaching and learning model

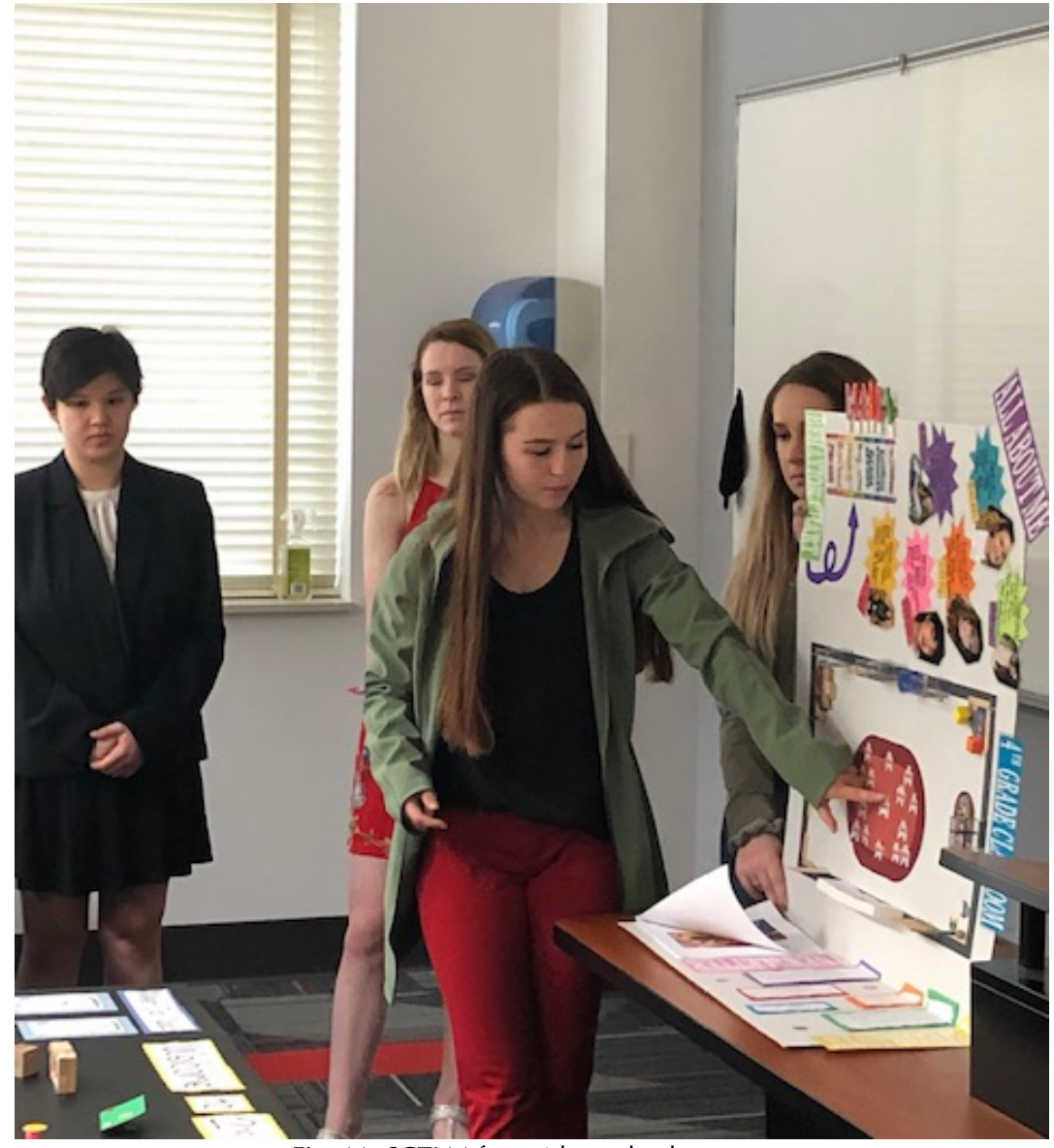

Fig. 11: SCTLM for a 4th-grade classroom 
In each case, the teams explained why they decided to construct their particular model and the reason that they included particular concepts into their models. Most students decide to construct some type of display using materials from our Maker Space, although I have had students write a script and dramatize it or produce a video. In all cases, the SCTLM is used to further try and connect theory to practice.

\section{Performances and Evaluation}

Performances have received a lot of attention across different fields and contexts (see Darling-Hammond, 2006; Davis, Montjoy, \& Palmer, 2016; Galluzzo, 2005; Govaerts, 2016; Sambell, McDowell, \& Montgomery (2012); Stosich, Snyder, \& Wilczak, 2018; Struyven, Blieck, \& De Roeck, 2014). Since performances are an integral component of the class described in this study, it is essential that these performances are included when evaluating course quality and outcomes. Our university administers a standard course evaluation that asks students to rate various dimensions of instructor, exams, and assignments quality from "strongly agree" to "strongly disagree"; however, these ratings do not explicitly refer to performances, but rather focus more on organization and clarity. Because faculty are also encouraged to conduct their own evaluations to determine to what extent students have achieved important course outcomes, I constructed my own "outcomes" evaluation, but also included a question on instructional practices as follows:

In relation to the instructional practices of flipping, integrated assessment, and dramatizations/performances, to what degree have you grown in terms of learning and a positive attitude towards teaching?

\begin{tabular}{|ccccc|}
\hline 1 & 2 & 3 & 4 & 5 \\
Lone & Little & Some & Much & A Great Deal \\
Can you comment briefly below how these practices have had an impact on your learning and attitude?
\end{tabular}

Over the past several years, approximately 90 to $95 \%$ of students have rated this question with a 4 or 5 response. While this average rating is gratifying, there are still those students who seem to prefer traditional instruction where the teacher delivers content while students dutifully take notes. Moreover, this is a source of both disappointment and concern since most of these students are preparing to become classroom teachers. However, I like to think that this is unfortunately based on their past experience with teaching and learning and that they will eventually come to the realization that such passive teaching practices do not motivate most students to want to learn and may also lead to early teacher burnout since not only do students get bored, but also teachers. 


\section{Conclusion}

I have found that integrating performances into a flipped classroom environment can be an engaging and effective way to facilitate both cognitive and attitudinal development. Having "fun" in a classroom through performances and dramatization can also challenge students to continue to grow and learn. I cannot envision returning to the days where I "delivered" content primarily through direct instruction, whether I am teaching undergraduate students or doctoral students—I have seen too many benefits based on both my own observations and student evaluations. There is, however, always room for improvement and the best way to achieve this is asking for, thoughtfully considering, and then acting upon student suggestions. This kind of quest has resulted in continued motivation to learn for both students and teacher.

\section{References}

Bastian, K.C., Lys, D., \& Pan, Y. (2018). A framework for improvement: Analyzing performanceassessment scores for evidence-based teacher preparation program reforms. Journal of Teacher Education, 69(5), 448-462. doi:10.1177/0022487118755700.

Bernauer, J.A., \& Cress, K. (1997). How school communities can help redefine accountability assessment. Phi Delta Kappan, 79(1), 71-75.

Bernauer, J.A., \& Tomei, L.A. (2015). Integrating pedagogy and technology. Rowman \& Littlefield.

Castle, S., \& Shaklee, B.D. (2006). Assessing teacher performance. Rowman \& Littlefield Education.

Cooper, N., \& Garner, B.K. (2012). Developing a learning classroom: Moving beyond management through relationships, relevance, and rigor. Corwin.

Darling-Hammond, L. (2006). Assessing teacher education: The usefulness of multiple measures for assessing program outcomes. Journal of Teacher Education, 57(2), 120-138.

Davis, T.S., Montjoy, K.J., \& Palmer, E.L. (2016). The Journal of Research in Business Education, 57(2), $1-14$.

Dewey, J. (1913). Interest and effort in education. Houghton-Mifflin.

Galluzzo, G.R. (2005). Performance assessment and renewing teacher education: The possibilities of the NBPTS standards. The Clearing House, 78(4), 142-146.

Govaerts, M.B. (2016). Competence in assessment: Beyond cognition. Medical Education, 50, 502-504.

Kaplan, M., Silver, N., Lavaque-Manty, D., \& Meizlish, D. (2013). Using reflection and metacognition to improve student learning. Stylus Publishing, LLC.

Kubiszyn, T., \& Borich, G. (1993). Educational testing and measurement (4th ed.). HarperCollins.

Maxwell, T.W. (2012). Assessment in higher education in the professions: Action research as an authentic assessment task. Teaching in Higher Education, 17(6), 686-696. 
Mayer, R.E. (1984). Twenty-five years of research on advance organizers. Instructional Science, 8, 133-169.

Morris, L.L., Fitz-Gibbon, C.T., \& Lindheim, E. (1987). How to measure performance and use tests. Sage.

Piaget, J. (1954). The construction of reality in the child. (M. Cook, Trans.). Basic Books.

Polanyi, M. (1958). Personal knowledge. The University of Chicago Press.

Sambell, K., McDowell, L., \& Montgomery, C. (2012). Assessment for learning in higher education. Routledge.

Stosich, E.L., Snyder, J., \& Wilczak, K. (2018). How do states integrate performance assessment in their systems of assessment. Education Policy Analysis, Archives 26(13), 1-32.

Struyven, K., Blieck, Y., \& De Roeck, V. (2014). The electronic portfolio as a tool to develop and assess pre-service student teaching competencies: Challenges for quality. Studies in Educational Evaluation. doi:10.1016/j.stueduc.2013.06.001

Vygotsky, L.S. (1978). Mind in society: The development of higher mental process. Harvard University Press.

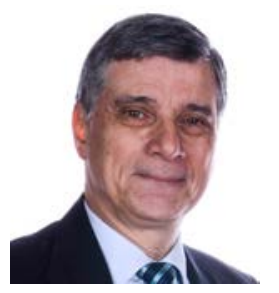

James A. Bernauer graduated from the University of Dayton in secondary education social studies and later earned a master's degree in the education of students who are deaf and has taught at the middle and high school levels. He earned his doctorate from the University of Pittsburgh and taught in the schools of education at Boston College, Duquesne University, and the University of Pittsburgh. He is currently a Professor of Education at Robert Morris University in Pittsburgh, where he teaches at the undergraduate, master's, and doctoral levels in the areas of educational psychology, qualitative research, and quantitative research. 